\title{
Concomitant Use of Single Suture Anchor and Transosseus Repair Provide Optimal Results in Simultaneous Bilateral Quadriceps Tendon Rupture: A Case Report
}

\author{
Husnul Fuad Albar ${ }^{1}$ (D), Permana Yudhadibrata ${ }^{2}$ iD Arya Widjaja $^{1 *(\mathbb{D})}$ \\ ${ }^{1}$ Department of Orthopaedic and Traumatology, Sport Division, Faculty of Medicine, University of Sumatera Utara, Haji Adam \\ Malik General Hospital, Medan, Indonesia; ${ }^{2}$ Department of Orthopaedic and Traumatology, Sport Division, Haji Hospital, \\ Medan, Indonesia
}

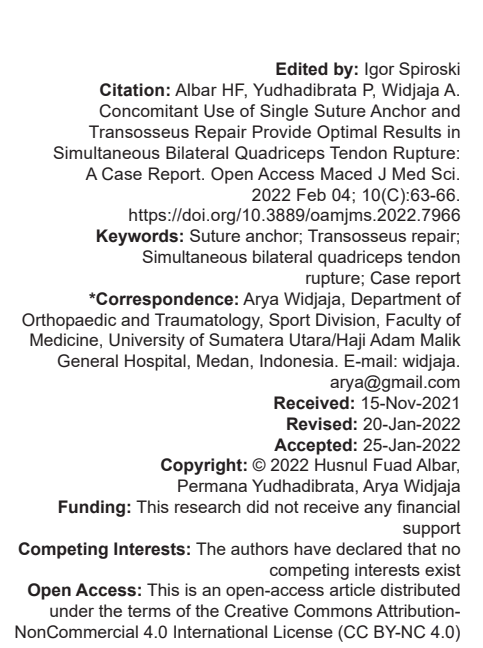

\section{Abstract}

BACKGROUND: Bilateral quadriceps tendon rupture is a rare condition and often associated with underlying medical comorbidities such as chronic renal insufficiency.

AIM: This case report is aimed to evaluate the surgical outcome using the combination of suture anchor and transosseus repair technique.

PRESENTATION OF CASE: Presenting a 54-year-old male who sustained a simultaneous bilateral quadriceps tendon rupture with a history of right nephrectomy, chronic kidney disease with intermittent hemodialysis. He came with sudden bilateral knee pain, history of falling, and inability to walk since 3 weeks before admission to the hospital. Tenderness above the superior pole on both patella accompanied with slight swelling and no active range of motion of either knee joint was found on physical examination. Complete rupture of the quadriceps tendon of both knees at their osseus-tendon junction was revealed on magnetic resonance imaging. Recent literatures suggested that transosseus technique offers the safest and more stable tendon reattachment, while suture anchor provides biomechanical superiority. We tried to combine these advantages by incorporating both methods. Progressive active knee motion exercise was performed shortly after using the Kocher slab for 2 weeks. Subsequently, the patient can achieve painless, active extension and active 90-120 knee flexion 1 month postoperatively.

CONCLUSION: The application of a single suture anchor with transosseus repair in quadriceps tendon rupture led to an optimal outcome, improved stability, and earlier rehabilitation.

\section{Introduction}

Simultaneous bilateral quadriceps tendon rupture was first described by Steiner and Palmer in 1949 [1]. This rare condition generally involves patient older than 40 years of age with chronic metabolic abnormalities. Hyperparathyroidism, diabetes mellitus, steroid and fluoroquinolone medication, systemic lupus erythematosus, and rheumatoid arthritis were previously mentioned as a risk factor for bilateral quadriceps rupture [2]. Chronic renal insufficiency is the most frequent comorbidity in patients with this pathology [3].

Gold standard management is to drill holes in the patella with or without augmentation, which can be done with wire, Leeds-Keio ligament, Dacron tape, or Mersilon tape [4]. Suture anchor has also been used to repair a torn quadriceps tendon and shown comparable results to transosseus suture [5], [6], [7], [8], [9]. Transosseus repair ensures safety and stability [10], while suture anchor has their biomechanical advantage regarding higher load to failure, less gap formation, and overall stiffness [11].

We utilize the combination of transosseus repair and suture anchor technique for a patient with simultaneous bilateral quadriceps tendon rupture, who requiring intermittent dialysis for his chronic kidney disease. This work has been reported in line with the SCARE criteria [12].

\section{Presentation of Case}

A 54-year-old male, who works as an office worker, presented to our outpatient clinic with sudden bilateral knee pain, history of falling, and inability to walk since 3 weeks before admission to the hospital. $\mathrm{He}$ had a 6 years history of dialysis for end-stage renal 
disease. He also underwent right nephrectomy in 2000 due to renal stone. Daily activity was not limited before the incident. Goal of the treatment is to restore the function of the patient.

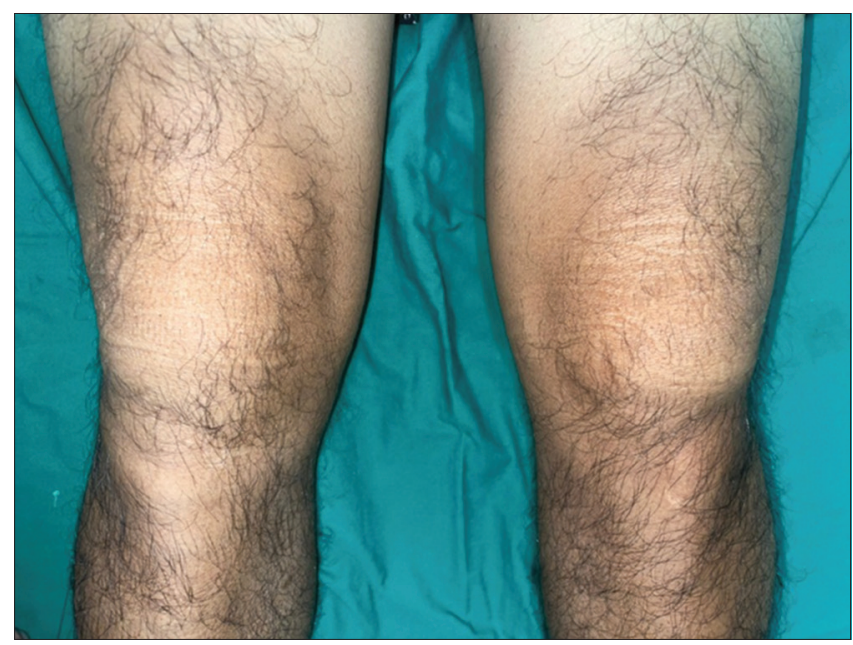

Figure 1: Clinical picture of both knees showing slight swelling

Tenderness above the superior pole on both patella accompanied with slight swelling and no active range of motion (ROM) of either knee joint was found on physical examination (Figure 1). Plain X-ray revealed patella Baja and loose patellar tendon. Complete rupture of the quadriceps tendon of both knees at their osseustendon junction was revealed on sagittal T2-weighted magnetic resonance imaging (MRI) (Figure 2). Laboratory examinations showed evidence of chronic renal insufficiency (Ur, $81 \mathrm{mg} / \mathrm{dL}$ and $\mathrm{Cr}, 12.59 \mathrm{mg} / \mathrm{dL}$ ). Histopathological examination was obtained after the surgery to seek intratendinous calcific deposition. This examination revealed numerous multinucleated giant cells possibly related to a Giant cell tumor, but no sign of neoplasm was found on the patient (Figure 3). These findings might be due to tissue regeneration after injury.
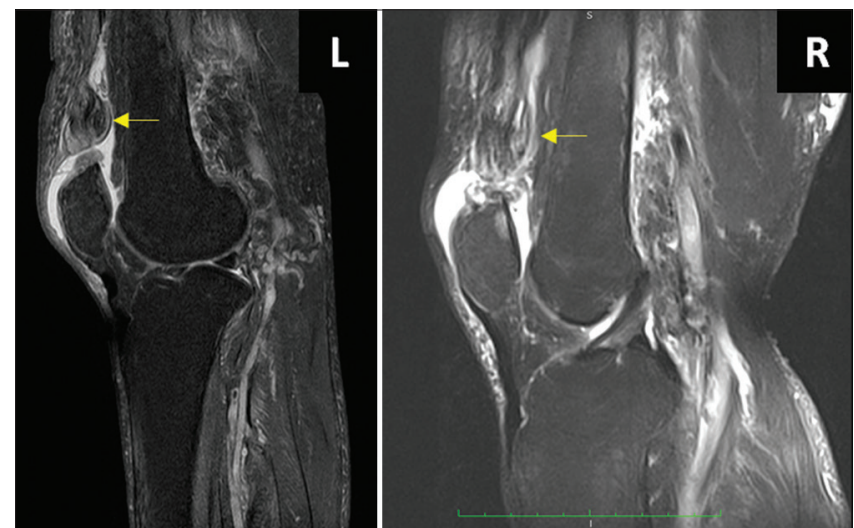

Figure 2: Sagittal T2W images of both knees showed complete distal quadriceps tendon rupture at their osseus-tendon junction

Surgery was done by orthopedic consultants. The patient was in supine position under general anesthesia. Similar surgical steps were performed on both knees. Anterior midline incision was used. The quadriceps tendon was completely ruptured at their osseus-tendon junction. Medial and lateral retinaculum were intact. Two bone tunnels were created with a 3.2-mm drill bit on proximal patella pole and the tendon was directly sutured to the upper pole of the patella with non-absorbable suture (no.2 Ethibond), using a Krackow technique. Additional stability was achieved through the application of a single-suture anchor (Healicoil $^{\circledR}$; Smith and Nephew) (Figures 4 and 5).

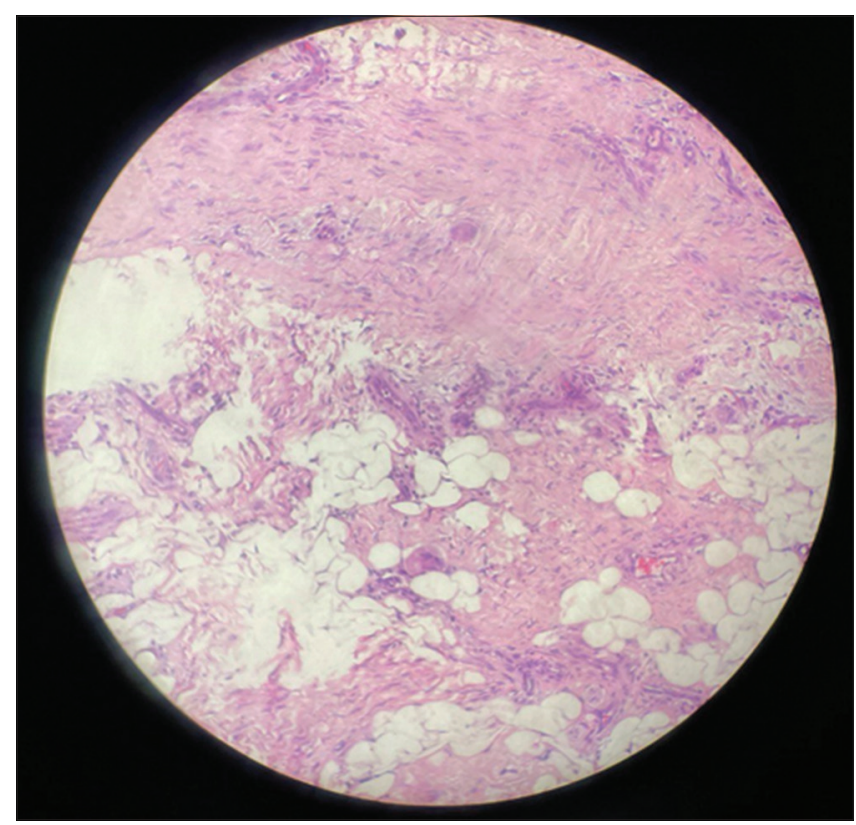

Figure 3: Histopathological examination revealed a number of giant cells possibly related to tissue regeneration

Both knees were immobilized using Kocher slab for 2 weeks. Routine examination was advised for the patient. Gradual active knee motion exercise using a walker and physical therapy was applied soon after removal of the slab. 1 month after surgery, the patient can achieve pain-free, active extension, and $90^{-} 120^{\circ}$ active knee flexion. Full, painless active flexion, and extension were achieved at 2 months postoperatively (Figure 6), Tegner-Lysholm knee score for the right and left knee was 98 (excellent) and 93 (excellent) respectively, quadriceps muscle strength was five (normal) based on Medical Research Council.

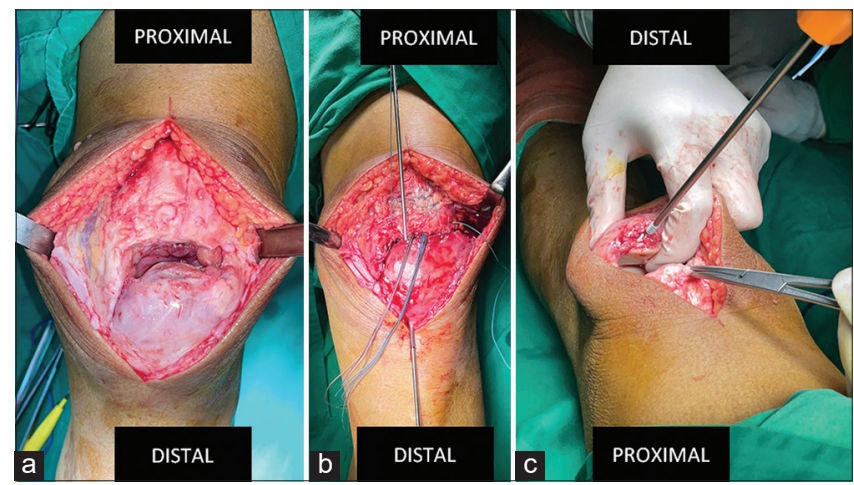

Figure 4: Repair of the quadriceps tendon rupture. (a) Complete rupture of the quadriceps tendon at the osseus-tendon junction; (b) Bone tunnel construction; (c) Application of suture anchor 
Full weight-bearing was accomplished after 3 months and the patient is advice to do isotonic exercise, increase flexibility, and regular checkups for his chronic kidney problems.

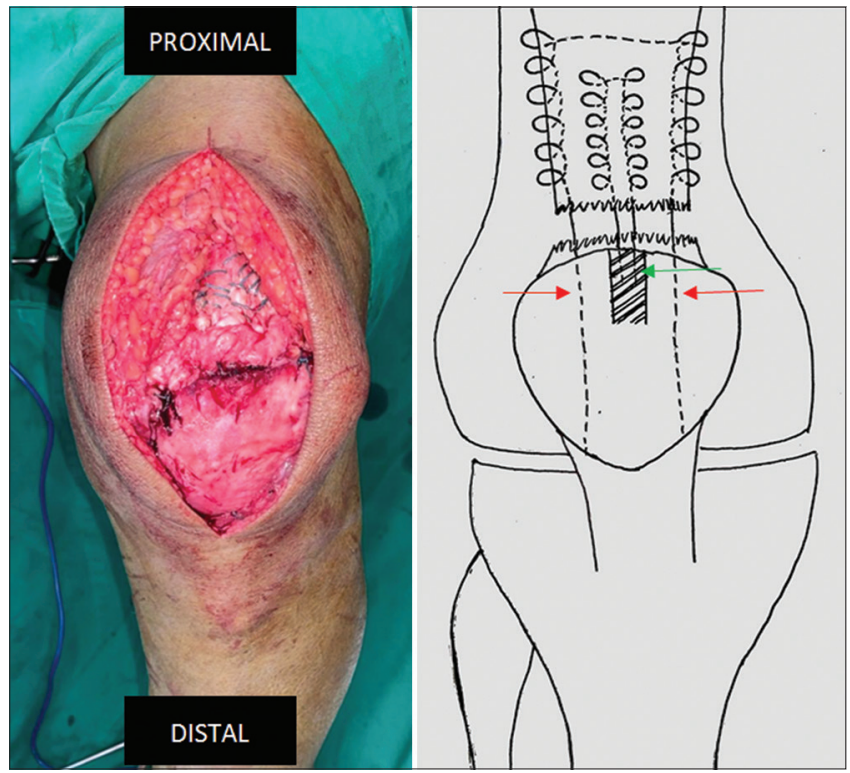

Figure 5: Final construct of the surgery; (red arrow) transosseus and (green arrow) suture anchor

\section{Discussion}

This case report describes the employment of both transosseus repair and suture anchor in a patient with bilateral quadriceps tendon rupture. Our clinical results indicated that combination of both techniques gives an excellent outcome, improves stability, and permits immediate functional rehabilitation for the patient. This method could provide an alternative treatment for quadriceps tendon rupture.
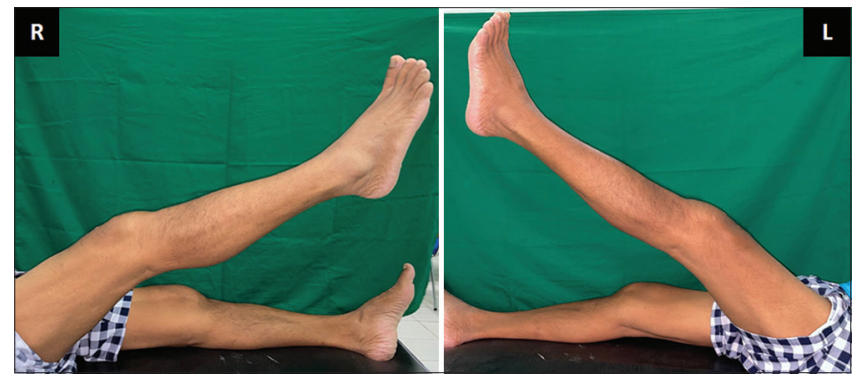

Figure 6: Full extension of both knees was achieved at 8 weeks after surgery

No literature source has yet been found that provides statistical data demonstrating the most appropriate surgical management for this condition. Patel and Carayannopoulos [13] and Arumilli et al. [14] restored the ruptured tendon using the gold standard, transosseus repair technique through non-absorbable suture. Full weight-bearing activities were documented at 6 months and 6 weeks after surgery, respectively. FiberWire $₫$ was also used to firmly grasp the tendon and pull it toward the patella. The patient has fully resumed all his sports activities within 2 years of surgery [15]. Kim et al. [16] repaired the tendon using a non-absorbable suture through six bone tunnels, sutured tendons to superior patella with Krackow technique, and added Bio-Mini Revo (Linvatec) bioabsorbable suture screws. Active knee extension and normal quadriceps muscle strength were achieved at 4 months after surgery.

We recommend biological therapy with stem cells, platelet-rich plasma, or local recombinant parathyroid injection for the future study, which might further enhance tendon healing in such cases and may hold real promise as a breakthrough treatment [17], [18], [19]. Our limitation of study is that we could not provide post-operative MRI images and we also did not include any biological enhancement due to the restriction of facilities available.

\section{Conclusion}

We present a case of bilateral quadriceps tendon rupture that occurred after a trivial injury in a 54-year-old male with history of the right nephrectomy and chronic renal failure. Tendon repairs have been successfully performed using a suture anchor and transosseus repair technique. Rehabilitation was permitted as early as 2 weeks after surgery. This technique achieved normal quadriceps muscle strength at 2 months postoperatively and full weight-bearing after 3 months.

\section{Consent}

Written informed consent was obtained from the patient for publication of this case report and accompanying images. A copy of the written consent is available for review by the Editor-in-Chief of this journal on request.

\section{Author Contributions}

Husnul Fuad Albar, Orthopedic Surgeon: Manuscript design and writing, literature review, and data collection. Permana Yudhadibrata, Orthopedic Surgeon: Manuscript design and writing, literature review, and data collection. Arya Cipta Widjaja: Manuscript design and writing, literature review, and data collection. 


\section{Guarantor}

Husnul Fuad Albar, Orthopedic Surgeon.

\section{References}

1. Steiner CA, Palmer LH. Simultaneous bilateral rupture of the quadriceps tendon. Am J Surg. 1949;78(5):752-5. https://doi. org/10.1016/0002-9610(49)90317-7

PMid:15391185

2. Miller MD, Thompson SR. Orthopaedic Sports Medicine: Principles and Practice. $5^{\text {th }}$ Edition. Philadelphia, PA: Elsevier; 2020.

3. Camarda L, D'Arienzo A, Morello S, Guarneri M, Balistreri F, D'Arienzo M. Bilateral ruptures of the extensor mechanism of the knee: A systematic review. J Orthop. 2017;14(4):445-53. https://doi.org/10.1016/j.jor.2017.07.008 PMid:28819342

4. Ilan D, Tejwani N, Keschner M, Leibman M. Quadriceps tendon rupture. J Am Acad Orthop Surg. 2003;11(3):192-200. https:// doi.org/10.5435/00124635-200305000-00006 PMid: 12828449

5. BrossardP, Le Roux G, Vasse B. Acute quadriceps tendon rupture repaired by suture anchors: Outcomes at 7 years' follow-up in 25 cases. Orthop Traumatol Surg Res. 2017;103(4):597-601. https://doi.org/10.1016/j.otsr.2017.02.013 PMid:28373140

6. Bushnell BD, Whitener GB, Rubright JH, Creighton RA, Logel KJ, Wood ML. The use of suture anchors to repair the ruptured quadriceps tendon. J Orthop Trauma. 2007;21(6):407-13. https://doi.org/10.1097/BOT.0b013e31806dd93b PMid:17621001

7. Maniscalco P, Bertone C, Rivera F, Bocchi L. A new method of repair for quadriceps tendon ruptures. A case report. Panminerva Med. 2000;42(3):223-5.

PMid:11218630

8. Mille F, Adam A, Aubry S, Leclerc G, Ghislandi X, Sergent P, et al. Prospective multicentre study of the clinical and functional outcomes following quadriceps tendon repair with suture anchors. Eur J Orthop Surg Traumatol. 2016;26(1):85-92. https://doi.org/10.1007/s00590-015-1710-6 PMid:26441330

9. Plesser S, Keilani M, Vekszler G, Hasenoehrl T, Palma S, Reschl M, et al. Clinical outcomes after treatment of quadriceps tendon ruptures show equal results independent of suture anchor or transosseus repair technique used a pilot study. PLoS
One. 2018;13(3):e0194376.

PMid:29554109

10. Iosifidis M, Lyrtzis C, Vasiliadis AV, Metaxiotis D. Easy and safe repair of quadriceps tendon rupture through transosseus sutures: A technical note. J Arthrosc Surg Sports Med. 2021;2(2):124-7.

11. Tramer JS, Evans H, Ziedas AC, Swantek AJ, Jordan SE, Makhni EC. Quadriceps tendon repair using double-row suture anchor fixation. Arthrosc Tech. 2021;10(10):e2337-42. https:// doi.org/10.1016/j.eats.2021.07.012

PMid:34754743

12. Agha RA, Franchi $T$, Sohrabi $C$, Mathew $G$, for the SCARE Group. The SCARE 2020 guideline: Updating consensus surgical case report (SCARE) guidelines. Int J Surg. 2020;84:226-30. https:// doi.org/10.1016/j.ijsu.2020.10.034

PMid:33181358

13. Patel M, Carayannopoulos NL. Simultaneous bilatera quadriceps tendon rupture with remote, short-term, low-dose statin use. Curr Orthop Pract. 2017;28(1):112-5.

14. Arumilli B, Adeyemo F, Samarji R. Bilateral simultaneous complete quadriceps rupture following chronic symptomatic tendinopathy: A case report. J Med Case Rep. 2009;3(1):9031.

15. Abduljabbar FH, Aljurayyan A, Ghalimah B, Lincoln L. Bilateral simultaneous quadriceps tendon rupture in a 24-year-old obese patient: A case report and review of the literature. Case Rep Orthop. 2016;2016:4713137. https://doi. org/10.1155/2016/4713137

PMid:27840757

16. Kim BS, Kim YW, Song EK, Seon JK, Kang KD, Kim HN Simultaneous bilateral quadriceps tendon rupture in a patient with chronic renal failure. Knee Surg Relat Res. 2012;24(1):56-9. https://doi.org/10.5792/ksrr.2012.24.1.56

PMid:22570854

17. Langenhan $R$, Baumann $M$, Ricart $P$, Hak $D$, Probst $A$ Badke $A$, et al. Postoperative functional rehabilitation after repair of quadriceps tendon ruptures: A comparison of two different protocols. Knee Surg Sports Traumatol Arthrosc. 2012;20(11):2275-8. https://doi.org/10.1007/ s00167-012-1887-8

PMid:22307751

18. Oh JH, Kim DH, Jeong HJ, Park JH, Rhee SM. Effect of recombinant human parathyroid hormone on rotator cuff healing after arthroscopic repair. Arthrosc J Arthrosc Relat Surg. 2019;35(4):1064-71. https://doi.org/10.1016/j. arthro.2018.11.038

PMid:30857903

19. Leong DJ, Sun HB. Mesenchymal stem cells in tendon repair and regeneration: Basic understanding and translational challenges. Ann N Y Acad Sci. 2016;1383(1):88-9. https://doi. org/10.1111/nyas. 13262

PMid:27706825 